DOI 10.37882/2500-3682.2021.02.07

\title{
АНАЛИЗ СТРУКТУРЫ МЕНТАЛЬНОЙ МОДЕЛИ СОЦИАЛЬНОЙ ОТВЕТСТВЕННОСТИ БИЗНЕСА В ПРЕДПРИНИМАТЕЛЬСКОЙ СРЕДЕ И НАСЕЛЕНИЯ, НЕ СВЯЗАННОГО С БИЗНЕСОМ
}

\section{ANALYSIS OF THE STRUCTURE \\ OF THE MENTAL MODEL OF SOCIAL RESPONSIBILITY OF BUSINESS \\ IN THE BUSINESS ENVIRONMENT AND THE POPULATION NOT ASSOCIATED WITH BUSINESS}

A. Ivanenko

Summary: The article presents an analysis of the structure of the mental model of social responsibility of business. The structure of the mental model itself is indicated on the basis of approaches to its study. The structure of social responsibility of business is presented from the position of various researchers and their view on the content structure of this concept. The data of an empirical study of the structure of the mental model of social responsibility of business in the business environment and the population are presented. The article shows the similarities and differences in the content of the structural components of the mental model of social responsibility of business.

Keywords: structure of business social responsibility, mental model, structure of the mental model of business social responsibility.
$\mathrm{M}$ ентальная модель - обобщенное представление людей (группы людей) о каком-либо объекте или явлении, сформированном на основе практического опыта, прямого или косвенного. Соответственно, ментальная модель социальной ответственности бизнеса - это обобщенное представление о социальной ответственности бизнеса. Социальная ответственность бизнеса представляет собой совокупность ответственности и обязательств, которые несет организация, предприятие перед обществом. Социальная ответственность бизнеса, на сегодняшний момент, становится неотъемлемой частью политики предприятия, залогом социальной стабильности общества, фактором снижения социальной напряженности. Но, в связи с тем, что метальные модели людей различаются, то неизбежно возникают разногласия в понимании социальной ответственности бизнеса, его содержания, что и приводит к повышению напряжения, недовольства со стороны представителей бизнеса, населения и государства и росту недопонимания между ними. Соотнесение ментальных моделей разных слоев населения позволит исключить обозначенную проблемy.
Иваненко Алина Сергеевна

Аспирант, Российская академия народного хозяйства и государственной службы при Президенте РФ

maria.petrova2019@yandex.ru

Аннотация: В статье представлен анализ структуры ментальной модели социальной ответственности бизнеса. Обозначена структура самой метальной модели на основе подходов к ее изучению. Представлена структура социальной ответственности бизнеса с позиции различных исследователей и их взгляда на содержательную структуру этого понятия. Приведены данные эмпирического исследования структуры ментальной модели социальной ответственности бизнеса в предпринимательской среде и у населения. Показаны сходства и различия в содержании структурных компонентов ментальной модели социальной ответственности бизнеса.

Ключевые слова: структура социальной ответственности бизнеса, ментальная модель, структура ментальной модели социальной ответственности бизнеса.

Для понимания специфики ментальной модели в предпринимательской среде и у населения, необходимо, в первую очередь, исследовать структуру ментальной модели социальной ответственности бизнеса.

Анализ исследований, посвященных проблеме структуры ментальной модели социальной ответственности бизнеса, позволил выделить несколько подходов.

Первый подход - это исследование практического мышления, которое лежит в основе житейских обобщений, связанных с окружающей реальностью. Именно такого рода обобщения являются содержанием ментальной модели. Результатом исследований в рамках данного подхода стало понимание специфических особенностей обобщенных представлений о реальности, формирующейся в процессе практического мышления (Завалишина Д.Н., Корнилов Ю.К., Кулюткин Ю.Н., Коневой Е.В., Вагнер Р., Стернберг Р., С. Скрибнер и др. [6,7,8, $16,17,18]$.

Второй подход - это исследование ментальной модели в рамках теории конструктов Дж. Келли. Ментальная 
модель представляет собой результат структурирования индивидуального опыта человека. В рамках данного подхода ментальная модель представляет собой сложную иерархическую структуру, сходную со структурой конструкта [5].

Третьим подходом в понимании ментальной модели являются исследования социальных стереотипов и представлений. Так же как и социальный стереотип, ментальная модель характеризуется устойчивостью, структурированностью, схематичностью и обуславливается индивидуальным опытом человека $[1,3]$. В соответствии с этим подходом, ментальная модель является информационным компонентом социального стереотипа. Если понятие «информационный» понимать максимально широко, то в качестве структурного компонента ментальной модели можно выделить аффективный компонент, характеризующий отношение субъекта к объекту или явлению.

В качестве четвертого подхода можно выделить исследование ментальной модели, как образа мира. В соответствии с этим подходом, ментальная модель, как и образ мира, формируется в ходе анализа и осознания окружающей реальности, и так же имеет свою структуру, которая характеризуется иерархичностью, сложностью и многоуровневым характером. [2,10].

В рамках пятого подхода, опирающегося на когнитивную психологию, структура ментальной модели, рассматривается М.А. Холодной, которая предлагает две схемы анализа структуры ментального опыта: первая отражает уровневую иерархию структур, участвующих в процессе переработки информации. Вторая схема - анализ устройства ментального опыта, как психического образования и взаимосвязи его с другими сферами психического [11].

Что касается исследований непосредственно ментальной модели, то среди современных работы, можно выделить исследования И.Ю. Владимирова, посвященные анализу ментальной модели партнера по общению. В ходе данного исследования были выделены как характеристики ментальной модели, так и ее структура, которая включает в себя когнитивный компонент - это система знаний и представлений об объекте и явлении, и аффективный компонент, характеризующий отношение к объекту или явлению [4].

Кроме представлений о структуре ментальной модели, так же необходимо иметь представление о структуре самого объекта или явления, в нашем случае - это структура социальной ответственности бизнеса.

Исследование структуры социальной ответственности бизнеса, необходимо строить на основе преставлений о данном понятии и его содержательной структуре.
Каждый исследователь, формулируя понимание о социальной ответственности бизнеса, делал акцент на своем представлении содержательной структуры этого понятия.

Так Х. Боуэн включал в содержание структуры социальной ответственности бизнеса ценностные ориентации, на которые необходимо ориентироваться предпринимателю в своей деятельности, чтобы она стала носить социально ответственный характер [13]. К. Уолтон, М. Хелд делали акцент на объектах, на которые должна быть направлена социальная ответственность бизнеса, - это и общество, в широком смысле, и общественные социальные институты [19]. Т. Джонс, выделяя в качестве основного компонента социальной ответственности бизнеса объект, расширял это понятие, включая в него собственников компании, отдельных людей и общество в целом.

С. Сеси включал в СОБ направленность деятельности предприятия и принципы, на которых должна быть основана реализация социальной ответственности бизнеса. В качестве направленности он выделял внешнюю направленность, целью которой является удовлетворение ожидания общества. А основным принципом, по его мнению, является ориентация на социальные нормы и ценности общества [15].

А. Кэрролл в качестве объекта социальной ответственности бизнеса выделял общество, а в качестве основных сфер, на которые направлена реализация социальной ответственности, - экономическую, правовую, этическую и дискреционную [14].

С.П. Перегудов, акцентируя внимание на принципах, выделял добровольность и выход за рамки закона. Объектами, по его мнению, выступают различные социальные группы [9].

Структуру социальной ответственности бизнеса можно строить, исходя из разных позиций. Так, если рассматривать структуру социальной ответственности бизнеса, делая акцент на объекте КСО [12], то она выглядит следующим образом:

1. объект КСО;

2. субъект КСО;

3. принципы, на которых строится взаимодействие между объектом и субъектом КСО

Объектами КСО является широкий круг заинтересованных лиц - это те, кто вложил деньги в предприятие кредиторов, они заинтересованы в прибыли. Персонал, который стремится получать достойную заработанную плату и различные гарантии от предприятия. Потребители, которые заинтересованы в качественной и безопасной продукции. Общество, в целом, которое ждет от 
предприятия ответственного поведения, бережного отношения к окружающей среде, социальную поддержку и т.д. Государство, которое ждет, что предприятие будет осуществлять свою деятельность в рамках законодательной базы и участвовать в различных социальных программах на государственном уровне.

В ходе осуществления социальной ответственности предприятие или организация выполняет различные социальные роли: оно может выступать в качестве работодателя, объекта инвестиции по отношению к акционерам и инвесторам, в качестве производителя по отношению к потребителям, в роли участника гражданского общества по отношению к сообществу, и участника социального развития, если в качестве объекта КСО выступает государство.

Взаимодействие между объектом и субъектом при реализации КСО строится на системе определенных принципов: принципа системности, принципа комплексности, принципа интегрированности, принципа подотчетности, принципа адресности, принципа динамичности, принципа инновационности мероприятий и технологий ее реализации, принципа открытости, принципа кооперации, принципа результативности, принципа последовательности деятельность.

Так же взгляд на структуру социальной ответственности бизнеса можно строить, акцентируясь на направлениях: внешняя направленность - это когда социальная ответственность реализуется в направлении экологической, социальной сфер, общества в целом и помощи отдельным группам людей, в частности; и внутренняя направленность - это когда социальная ответственность реализуется в плане поддержки сотрудников предприятия.

Таким образом, анализ показал, что в качестве основных содержательных структурных компонентов социальной ответственности бизнеса можно выделить:

а) ценностные ориентации и ценностные приоритеты организации (предприятия);

б) объекты KCO;

в) направления КСO.

Именно сочетание этих компонентов позволяет выделить уровни развития КСО на каждом предприятии или организации.

На основе представления о том, что ментальная модель имеет две составляющие - когнитивную и аффективную, можно простроить следующую структуру ментальной модели социальной ответственности бизнеса (рис.1).

Эмпирическое исследование представлений о структуре (направленность, система приоритетных ценностей, объекты) ментальной модели социальной ответственности проводился при помощи письменного опроса на основе неоконченных предложений.

Всего в исследовании приняло участие 82 человека, из них 24 мужчины и 58 женщин средний возраст по выборке- 48,15 лет. Из них представители бизнеса- 55 че-

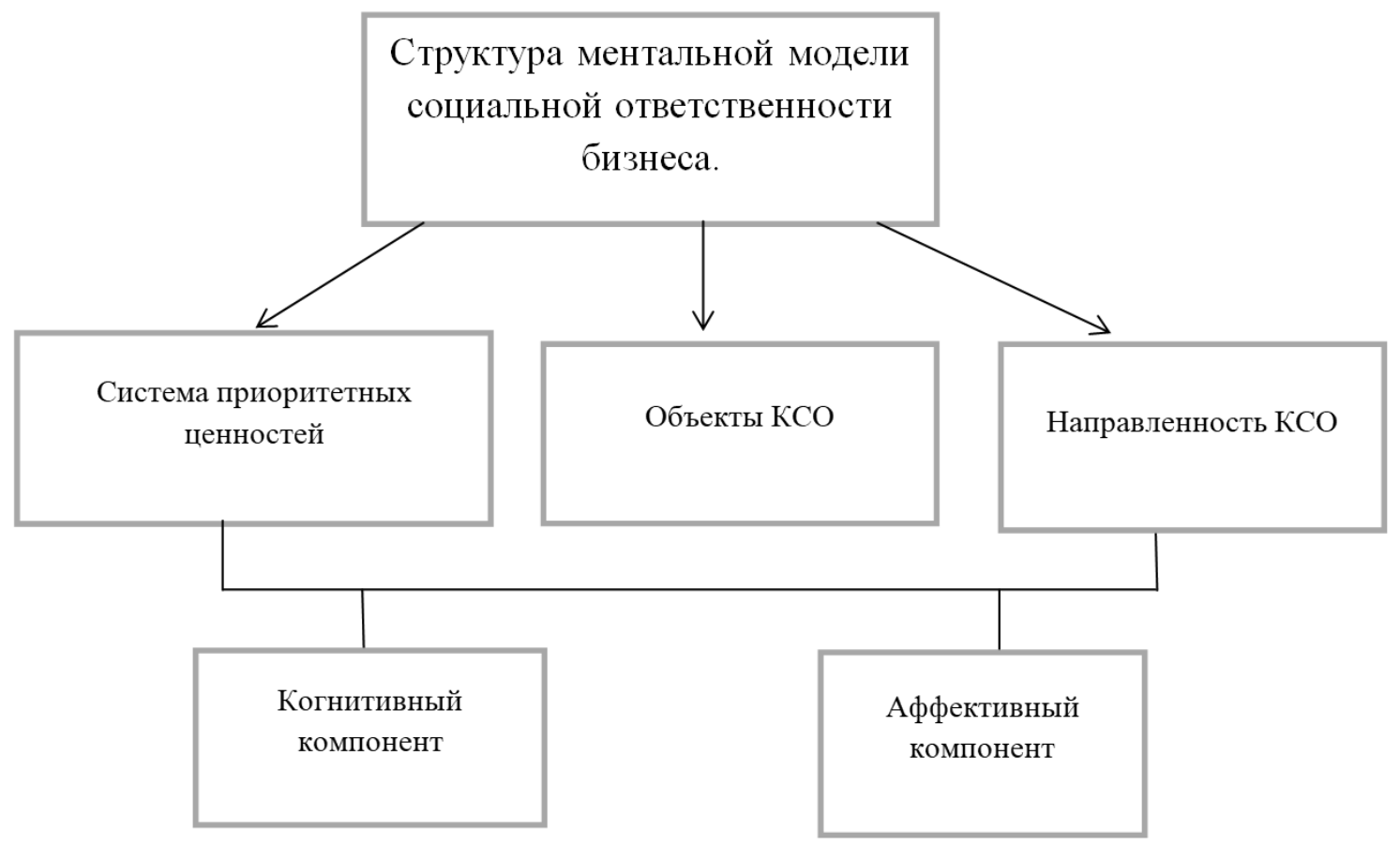

Рис. 1. Структура ментальной модели социальной ответственности бизнеса 
ловек, а так же испытуемые, занятые не в сфере бизнеса - 27 человек.

Анализ проводился на основе результатов предпринимателей высшего звена (руководителей, топ менеджеров крупного бизнеса) и населения, не занятого в сфере бизнеса.

Исследование объекта социальной ответственности в группе населения и предпринимательской среде позволило получить следующее распределение результатов (рис 2).

Анализ рисунка показывает, что в целом, представление об объектах социальной ответственности бизнеса у населения и предпринимателей высшего звена имеет существенные сходства. Различия заключаются в присутствии у предпринимателей такого объекта, как устойчивое развитие самого предприятия, т.е. непосредственно предприятие является объектом СОБ. Статистический анализ показал значимость различий в устойчивом развитии предприятии как объекта между руководителями и населением $\left(\varphi_{\text {эмп }}^{*}=2,221\right.$, при $\left.p<0,01\right)$.

Анализ приоритетных объектов СОБ у разных предпринимателей населения показали, что в группе руководителей - это:

1. работники;

2. экология и - устойчивое развитие (одинаковая приоритетность);

3. выпуск качественных и безопасных товаров.

В группе населения приоритеты объектов СОБ рас- пределились следующим образом:

1. экология;

2. работники;

3. выпуск качественных и безопасных товаров; - различные социальные программы (одинаковая приоритетность);

Таким образом, можно говорить о том, что в предпринимательской среде современных российских бизнесменов высшего звена социальные программы не относятся к приоритетным объектам СОБ. В то время как население считает это важным объектом и неотъемлемой частью социальной ответственности бизнеса.

Анализ направленности социальной ответственности бизнеса показывает, что в предпринимательской среде в приоритете внутренняя направленность - работников предприятия и качественные товары. У населения чаще встречается внешняя направленность: на общество в целом и отдельные группы населения.

Исследование представленности принципов в ментальной модели социальной ответственности бизнеса показывает, что единственный принцип, который выделятся в обеих группах, является принцип добровольности. Поскольку принцип добровольности был заложен рабочее определение социальной ответственности бизнеса, то акцент делался именно на анализе представлений о принципе добровольности СОБ у представителей бизнеса и населения. Вопрос был сформулирован следующим образом: Может ли социальная ответственность бизнеса быть добровольной? Распределение ответов представлено на рис.3

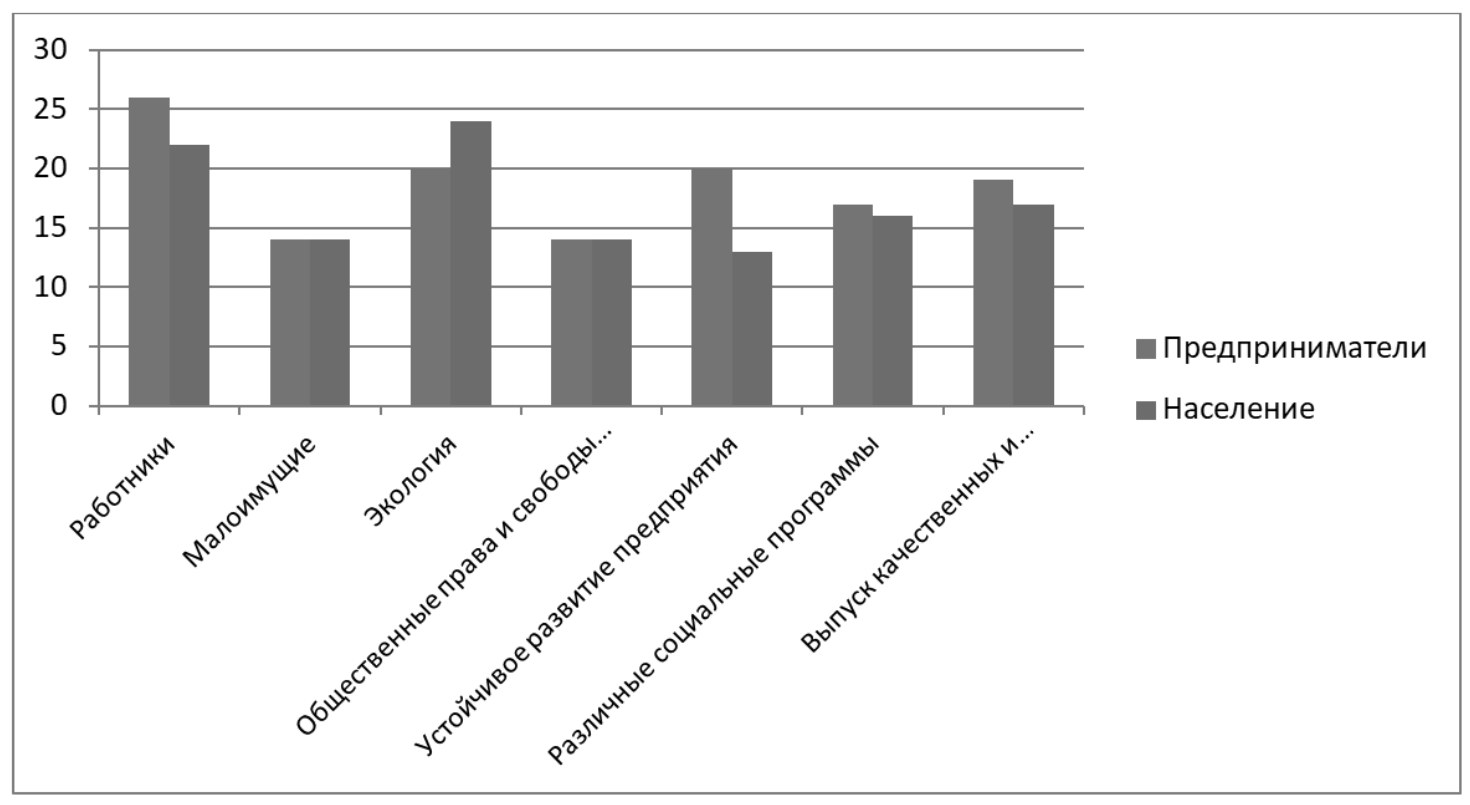

Рис. 2. Распределение удельного веса объектов социальной ответственности бизнеса у предпринимателей высшего звена и населения 


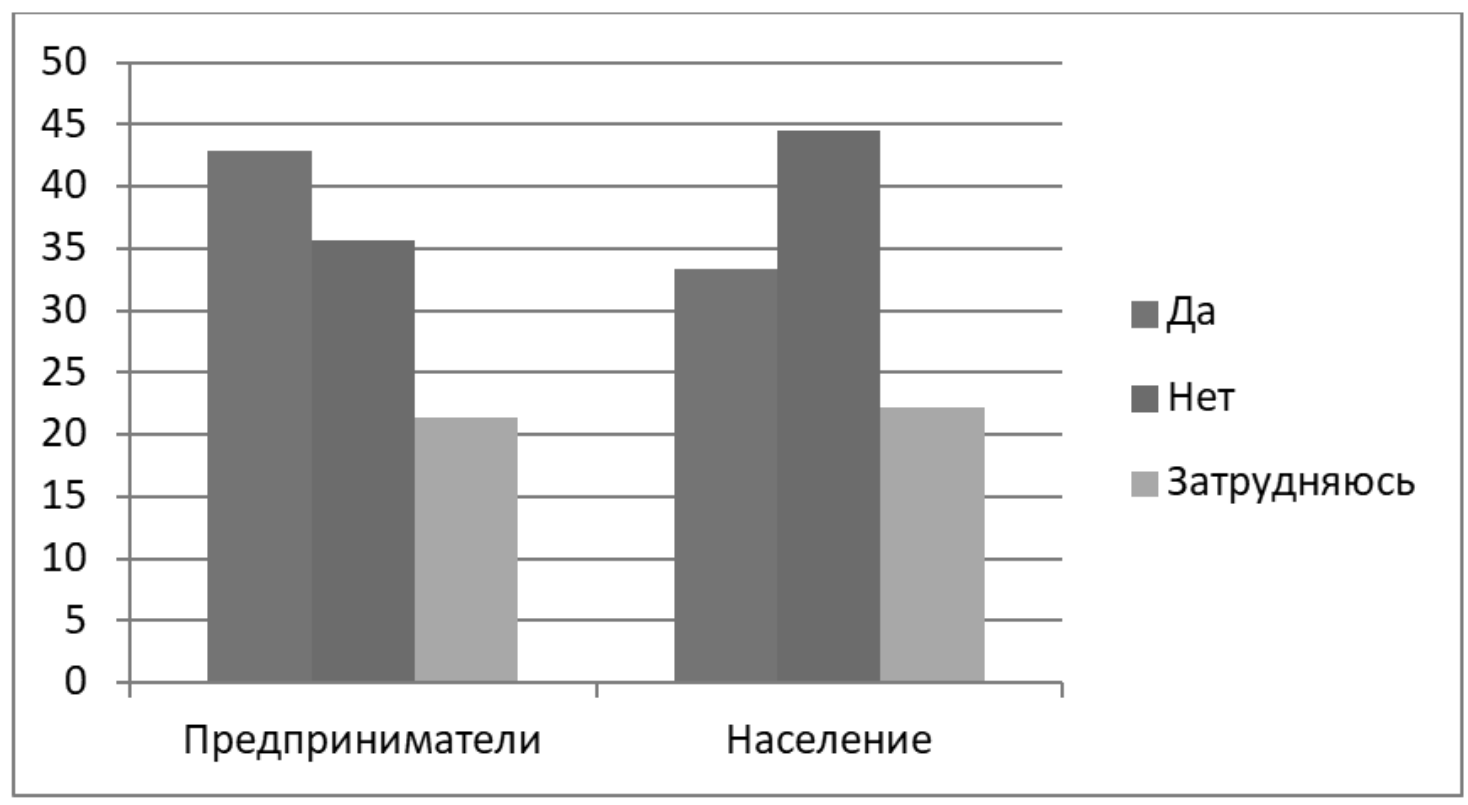

Рис. 3. Распределение удельного веса ответов о принципе добровольности в группе предпринимателей и населения

Анализ данных показывает, что практически половина представителей бизнеса считают, что социальная ответственность должна быть добровольной. В то время как среди испытуемых, не занятых в бизнесе, это всего лишь треть респондентов.

Таким образом, можно говорить о том, что в струк- туру ментальной модели социальной ответственности бизнеса предпринимателей и населения входят объект, направленность, принципы социальной ответственности. Наиболее существенные различия наблюдаются в содержании каждого структурного компонента. В особенности это касается объектов и направленности социальной ответственности бизнеса.

1. Агеев В.С. Межгрупповое взаимодействие. - М.: МГУ, 1990. 240 с.

2. Артемьева Е.Ю. Семантические измерения как модели // Вестник МГУ. Серия 14, Психология. № 1. 1991. С. 61 - 73.

3. Быструшкина Н.Г. Психологические аспекты ситуаций межнационального взаимодействия. Дисс. ...канд. психол. наук. Ярославль 1999.179 с.

4. Владимиров И.Ю. Особенности строения и функционирования ментальной модели партнера по общению: дисс. канд. психол. наук Ярославсль, 2004.236 c.

5. Забродин Ю.М., Похилько В.М. Теоретические истоки и значение репертуарных личностных методик //Новый метод исследования личности (предисловие). - М.: Прогресс, 1987. С. $5-26$.

6. Завалишина Д.Н. Обобщения в практическом мышлении // Мышление и общение в конкретных видах практической деятельности. Ярославль: ЯрГУ, 1984. C. 3-18.

7. Конева Е.В. Особенности мышления в субъект-субъектных видах деятельности. Некоторые детерминанты в мышлении следователя. // Психологический журнал. Т 17. № 6. 1996. С. 82 - 95.

8. Корнилов Ю.К. О видах направленности мышления // Ежегодник Российского Психологического общества. Материалы III всероссийского съезда психологов - СПб.: Изд-во СПбГУ 2003. Т. 4. С. $389-390$.

9. Перегудов С.П. Социальная ответственность бизнеса и корпоративное гражданство. Выступление на Ученом совете ИМЭМО РАН, 2005.

10. Смирнов С.Д. Мир образов и образ мира // Вестник МГУ. Серия 14, Психология. № 2. 1981. С. 15 - 29.

11. Холодная М.А. Психология интеллекта. - СПб.: Питер, 2002. 264 с.

12. Шиманская Е.В. Внутренняя отчетность как источник информации при проведении контроля за соблюдением положений коллективного договора // Все для бухгалтера. 2011. №2(2).

13. Bowen H.R. Social Responsibilities of the Businessman. New York: Harper and Row,1953.P. 151-163.

14. Carroll A.B. Corporate Social Responsibility: A Historical Perspective, in Epstein J.M, Hanson K.0. (eds.) The Accountable Corporation, vol. 3. Westport, Conn.: Praeger Publishers, 2006.

15. Sethi S.P. Dimensions of Corporate Social Performance: An Analytical Framework // California Management Review. 1975. № 17(3). 
16. Scribner S. Thinking in action: some characteristics of practical thought II Practical intelligence. Cambridge Un. Press, 1986. P. 13-30

17. Sternberg R. Theory and Measurement of Tacit Knowledge as a Part of Practical Intelligence IIZ Psycholros (1995) p. 319 - 334.

18. Wagner R.K., Sternberg R. J. Tacit Knowledge and intelligence in the everyday world II Practical intelligence. Cambridge Un. Press, 1986. P. 51 - 83.

19. Walton C.C. Corporate Social Responsibilities - Belmont, Calif: Wadsworth Publishing Co. Inc., 1967. P. 18

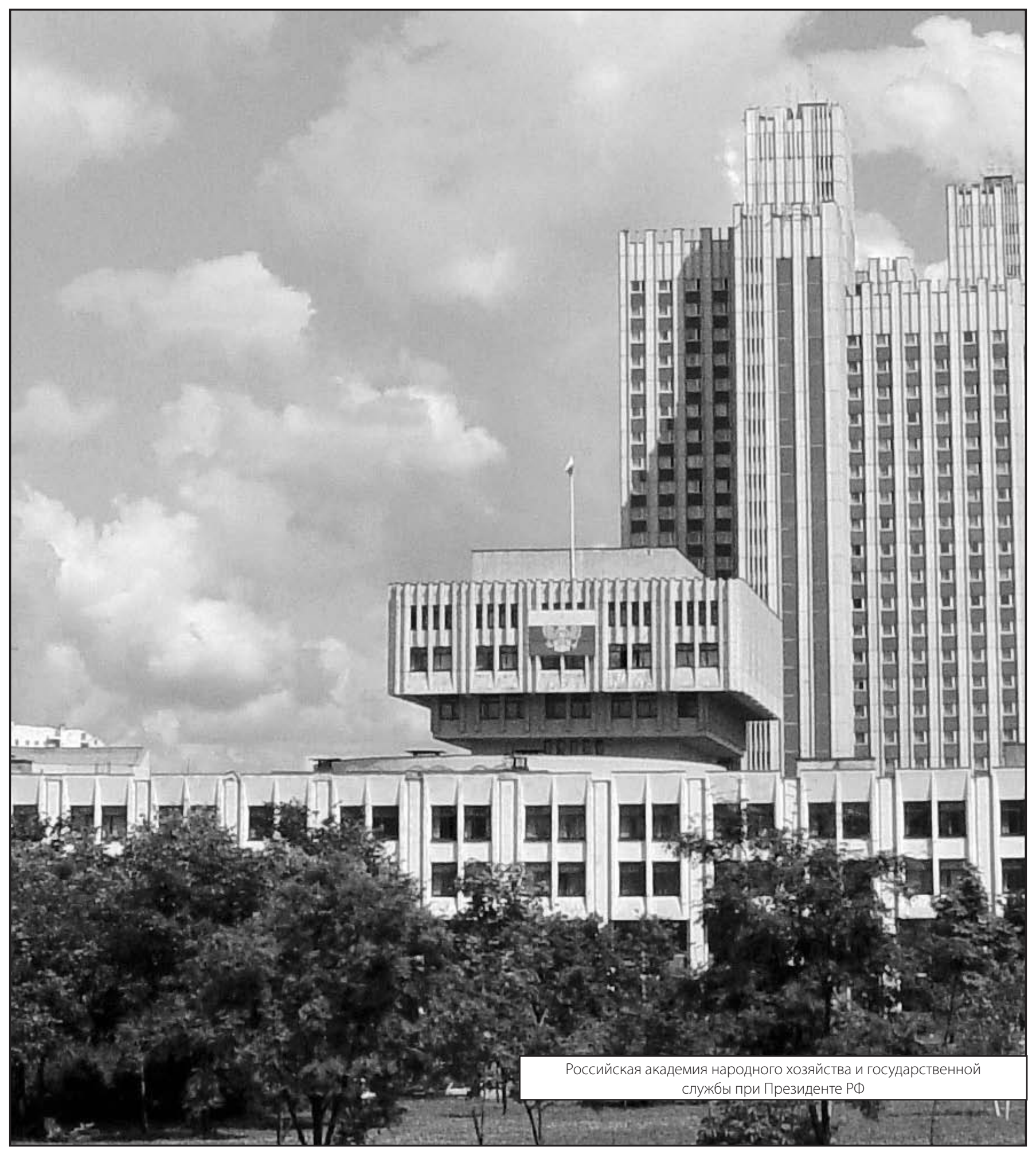

